\title{
Состояние тромботической готовности - возможности современной диагностики и перспективы
}

\author{
А. П. Момот, А.м.н., профо., Аиректор \\ И. А. Тараненко, К.М.Н., Ст. научный сотрудник \\ ^.П. Цывкина, А.М.н., профо., Ст. научный сотруАник \\ А^тайский фолиал ФГБУ «Гематологический научный центр» МинзАрава России, г. Барнаул \\ ГБОУ «ААтайский госуАарственный меАицинский университет» МинзАрава России, г. Барнаул
}

\section{Thrombotic state of readiness - the possibilities of modern diagnostics and prospects}

A.P. Momot, I. A. Taranenko, L.P. Tsyvkina

Altai Branch of FSBI Hematological Research Center, Ministry of Health of the Russian Federation, Barnaul

SBEI, the Altai State Medical University, Ministry of Health of the Russian Federation, Barnaul

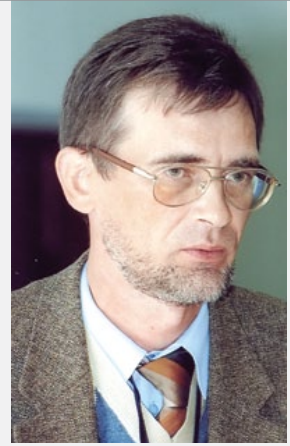

\section{Резюме}

В статье привоАятся новые взгяяАы на факторы тромбогенного риска, состояние тромботической готовности и тромбофимию. На основании собственных исслеАований опреАелена роль этих понятий в объяснении возникновения артериальных и венозных тромбозов. Выполнен краткий обзор современных ^абораторных методов оценки состояния тромботической готовности.

КАючевые слова: факторы тромбогенного риска, тромбофимия, состояние тромботической готовности, Аабораторные МетоАы исслеАования системь гемостаза.
Summary

The article provides new insights on thrombogenic risk factors, thrombotic state of readiness and thrombophilia. Based on our own research the role of these concepts is determined explaining the occurrence of arterial and venous thrombosis. A brief overview of current laboratory methods of state values of thrombotic state of readiness is fulfilled.

Keywords: thrombogenic risk factors, thrombophilia thrombotic state of readiness, laboratory methods of hemostasis.

А.П. Момот

$\mathrm{C}$ овременный уровень исследования системы гемостаза принципиально отличается от методических подходов второй половины XX века: диагностика клинически значимых нарушений гемостаза сегодня включает в себя обособленные группы методов, относящихся как к клинико-функциональным (проба Айви, манжеточная проба), так и «чисто» лабораторным способам распознавания нарушений свертывания крови, предусматривающим осуществление «әлобальных» методов исследования (компьютерная тромбоэластография, тест генерации тромбина, исследование томбодинамики), агрегометрии тромбоцитов, функциональных коагуляционных, так называемых «клоттинговых» или «хронометрических» проб (по оценке различных вариантов времени свертывания), амидолитических тестов с использованием хромогенных суб- стратов к тромбину, плазмину, фактору Ха, XIIIa, протеину С и др., иммунологическихметодов, позволяющих выявить уровень искомого антигена (или антител) при распознавании антифосфолипидного синдрома, гепарин-индуцированной тромбоцитопении II типа, гипергомоцистеинемии, при измерении уровня D-димеров, а также генетических методов выявления носительства мутаций и полиморфизмов генов - участников системы гемостаза и обмена метионина, предрасполагающих к тромбозу. Последняя группа методов приобрела большую популярность, поскольку данные исследования выполняются однократно на всем протяжении жизни. Однако при изолированном использовании (без определения маркеров реализации генетической предрасположенности и без учета тромботического анамнеза) они недостаточно информативны.
К сожалению, выполнение всех указанных традиционных и новаторских приемов для анализа нарушений в системе гемостаза не укладывается в функциональные обязанности любой современной лаборатории - гемостаза, клинической или биохимической, что является одним из серьезных противоречий в обеспечении потребностей современной медицины в данном виде медицинской помощи больным. Бесспорно, клинически значимое исследование системы гемостаза невозможно провести с помощью одного-двух наиболее современных методов исследования. Применение же комбинаций этих методов эффективно в рамках тех или иных алгоритмов обследования и не столько для статичного описания результатов, но для определения причин кровоточивости и внутрисосудистого тромбообразования, своевременного включения пациентов в группу высокого риска по кро- 


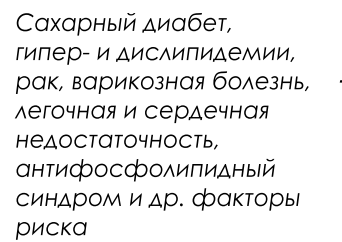

\section{Носительство} тромбогенных алмелей

FV ^ейАен (R506Q; G>A, rs6025)

Fll (G20210A; G>A, rs1799963)

PAl 1 (-675 5G/4G, rs1799889)

MTGFR (A223V C677T rs 1801133)

MTR (A2756G rs 1805087)

MTRR (A66G rs 1801394)

FI (G-455A rs 1800790)

ITGA2-a2 (C807T rs 1 126643)

ITGB3-b (T1565C rs5918)

и $А$ p. постоянные фракторы риска
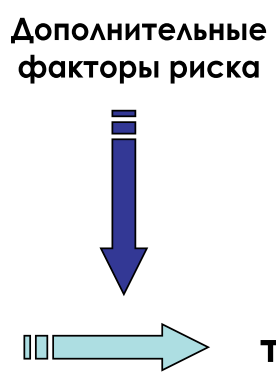

тромботической

Аополнительные факторы риска

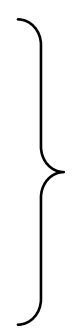

Операция, травма, лекарства беременность, многоп^одие, эстрогены, инфекция и $А р$. преходящие оракторы риска

Рис. Связь факторов тромбогенного риска, тромботической готовности и тромбофрилии в генезе тромбозов и неудач беременности.

вотечениям, тромбозам и тромбоэмболиям, адекватного контроля за эффективностью и необходимой длительности антитромботической терапии [1, 2].

Одно из важных направлений лабораторной диагностики нарушений гемостаза связано с проблемой «молодеющих» артериальных и венозных тромбозов, массивных тромбоэмболий, являющихся ведущей причиной снижения качества жизни, инвалидизации и летальности среди людей развитых стран мира. Больные с сосудистой ишемией и (или) окклюзией нуждаются в определении спектра лабораторных биомаркеров, указывающих не столько на наличие тех или иных врожденных или приобретенных факторов тромбогенного риска/тромбофилии, сколько на выявление состояния тромботической готовности, предшествующего и закономерно сопутствующего сосудистым катастрофам [3].

По опыту работы нашего центра и практике общения со специалистами - врачами различного профиля - можно констатировать неоднозначность трактовки и путаницу в понятиях «тромбофилия», «факторы тромбогенного риска» и «состояние гиперкоагуляции». Частое заблуждение среди клиницистов сегодня - замена понятия «фактор (или факторы) тромбогенного риска» на понятие «тромбофилия». Иными словами, носительство той или иной известной протромбогенной мутации или полиморфизма генов (участников гемостатических реакций и обмена метионина), как правило, рассматривается и диагностируется как тромбофилия, нанося моральный и иной вред пациентам (см. рис.). К сожалению, свой вклад вносит и неправомерное использование во врачебных заключениях слова «мутация» при определении полиморфизмов (а значит, вариантов нормы, по современным представлениям) ингибитора активатора плазминогена I типа (PAI 1), метилентетрагидрофолатредуктазы (MTHFR), фибриногена, рецептора тромбоцитов GP IIIA и ряда других.

В ходе клинико-генетических исследований, проведенных в период 2010-2012 гг. нашим центром совместно с лабораторией фармакогенетики Института химической биологии и фундаментальной медицины СО РАН (заведующий к. б. н. М. Л. Филипенко) и кафедрой педиатрии Алтайского государственного медицинского университета, в случайной выборке у 1915 жителей Алтайского края кавказской расы* без явных признаков соматической патологии, носительство хотя бы одной из четырех наиболее известных тромбогенных мутаций и полиморфизмов и цитируемых большинством авторов публикаций [FV Лейден (R506Q; G > A), F II (G20210A; G > A), PAI-1 (675; 5G/4G), MTHFR (A223V C677T; $\mathrm{C}>\mathrm{T})]$ установлено в $91,8 \%$ случаев $[3,4]$. Но это не значит, что все эти люди «страдают» тромбофилией и их необходимо лечить.

Остановимся на современных критериях диагностики одной из известных форм тромбофилии - антифосфолипидного синдрома (АФС). Согласно рекомендациям Международного общества по тромбозу и гемостазу (ISTH), диагноз АФС считается достоверным при сочетании хотя бы одного или более клинических проявлений данной патологии (сосудистый тромбоз, патология беременности) с результатами специальных лабораторных признаков (эффекты волчаночного антикоагулянта, антифосфолипидные антитела в диагностическом титре) [5]. Мы считаем возможным и необходимым распространить данный подход в диагностическую практику (обязательное сочетание тех или иных факторов риска наряду с состоявшимся тромбозом или синдромом потери

\footnotetext{
* Примеч. авторов - речь илет об обследовании лиц европеоилной расы, обозначаемой в зарубежных изданияхи посвященных генетике, как кавказская. В число обследованных не вошли представители монголоинной расы, проживающие на территории Горного Алтая, что существенно Аля оценки результатов. Возможна замена в тексте на «европеоидной».
} 
плода) на все возможные варианты тромбофилии, что позволит устранить терминологическую путаницу и системные ошибки в диагностике и определении тактики лечения.

Очевидно, что тромбофилия по существу не является болезнью, а представляет собой патологическое состояние, обусловленное комбинацией факторов риска, реализованных развитием тромбоза (тромбозов), информация о котором (которых) может быть получена по данным индивидуального анамнеза и соответствующей медицинской документации. Понимание и принятие данного положения имеет принципиально важное значение, поскольку восприимчивость к болезни не подразумевает под собой наличие показаний для медикаментозной тромбопрофилактики или проведения антитромботической терапии. Необходимо различать понятия «фактор тромбогенного риска» и «тромбофилия». Большинство людей - носителей постоянных или временных факторов риска тромбоза, им не страдают на протяжении длительного периода жизни, хотя и имеют вероятность развития этой патологии [6, 7]. Учитывая многолетний опыт мы считаем, что к факторам тромбогенного риска следует относить постоянные (генетически обусловленные) и временные (вторичные, действующие в определенный промежуток времени) индивидуальные особенности человека, беременность и внешние воздействия*, способные в различных сочетаниях привести к развитию тромботической готовности и в последующем к появлению тромбозов, тромбоэмболий, ишемий и инфарктов органов, серьезным и известным проблемам в области репродукции человека.

В настоящее время описано более 100 факторов тромбогенного риска, способных самостоятельно или чаще в своих сочетаниях привести к сосудистой катастрофе. К числу наиболее значимых факторов тромбогенного риска относятся:
- личный и семейный тромботический анамнез;

- глубокий дефицит физиологических антикоагулянтов (антитромбина III, витамин К-зависимых протеинов $\mathrm{C}, \mathrm{S}$, ингибитора внешнего пути свертывания - TFPI);

- образование в крови антифосфолипидных антител, в том числе обладающих свойствами волчаночного антикоагулянта;

- мутации и полиморфизмы генов участников гемостатических реакций (FV Лейден, F II, PAI-1, полиморфизм генов, участвующих в обмене метионина);

- стойкое увеличение концентрации и/или активности факторов свертывания крови: фибриногена, факторов II, VIII, IX или XI;

- ряд гематологических заболеваний, сопровождающихся патологией эритроцитов и тромбоцитов (врожденные полиглобулии, серповидноклеточная анемия, талассемия, синдром «липких» тромбоцитов);

- сосудистые аномалии (мальформации, артерио-венозные шунты, варикозная болезнь, повышенная извитость сонных артерий и др.), врожденные пороки сердца;

- наличие инородных тел в сердце и сосудах (протезы клапанов, стенты, фильтры, катетеры);

- тяжелые травмы и операции, сопутствующая гиподинамия и инфекционно-воспалительные процессы;

- злокачественные новообразования.

Термины «тромбофилия» и «повышенная свертываемость крови» часто используют как синонимы, в то время как на самом деле это понятия различны. Повышенная свертываемость крови или «гиперкоагуляционный синдром/состояние» - это лабораторный феномен, посредством которого специальными методами анализа системы гемостаза распознаются активация тромбоцитов и процессы образования фибрина, подавление фибринолитических реакций, повреждение эндотелия кровеносных сосудов.
Однако в практике повышенная склонность к тромбообразованию может сопровождаться парадоксальным, на первый взгляд, замедлением свертывания крови в связи с выработкой антифосфолипидных антител/волчаночного антикоагулянта или дисфибриногенемией при развитии варфариновых некрозов кожи или гепарин-индуцированной тромбоцитопении. Эти состояния противоречат смыслу терминов «гиперкоагуляционный синдром/состояние» и делают их несостоятельными и устаревшими $[2,3]$.

Нами предлагается альтернативное, клинически оправданное понятие - состояние тромботической готовности, которое способно объединить в себе лабораторно выявляемую гиперкоагуляцию, высокий уровень маркеров внутрисосудистого свертывания крови, а также ряд клинических признаков предтромбоза (увеличение вязкости крови, замедление кровотока по данным дуплексного ангиосканирования венозного кровотока, перманентные признаки органной дисфункции, тромбирование иглы при венепункции, нарушение фетоплацентарного кровотока, гипотрофия плода, нарушение сроков миграции или частичная отслойка плаценты и др.). Соответственно, реализация этой готовности при сохраняющихся факторах риска и их умножении (операцией, травмой, иммобилизацией, системным воспалительным процессом, онкологическим заболеванием, сахарным диабетом, сердечной недостаточностью, приемом эстрогенов, поздним сроком беременности) с высокой вероятностью способна проявиться сосудистой катастрофой [3].

Состояние тромботической готовности обычно формируется при кооперации различных факторов тромбогенного риска и непосредственно предшествует тромбозу или сопровождает его при неэффективности антитромботической терапии. При этом генетическая детерминированность не означает обязательную ее реализацию в данный момент времени в тех или иных сдвигах, спо- 
собствующих тромбозу или неудачам репродукции [8-10]. Так, мутация FV Лейден не обязательно проявляется тромбинемией и (или) повышением уровня D-димеров, полиморфизм генов, участвующих в обмене метионина, - повышением уровня гомоцистеина, а редкая гомозигота гена PAI I - повышением активности PAI I и угнетением фибринолитических реакций. Можно ожидать высокой вероятности этих событий, но когда и в какой мере - не поддается прогнозу и зависит от дополнительных факторов риска в тех или иных случаях, например, при обезвоживании или дистрессе.

С практической точки зрения, учитывая современные возможности клинико-диагностических лабораторий и наш опыт работы, можно считать необходимым определение следующих показателей тромбогенной опасности: повышения уровня маркеров тромбинемии и активации тромбоцитов, гипергомоцистеинемии, проявлений эндотелиопатии, полиглобулии, а также нарастания уровня C-реактивного белка как интегрального маркера воспалительной реакции, связанной с реакциями гемостаза [11-13]. Возможности совершенствования этого направления лабораторных исследований чрезвычайно интересны в связи с появлением новых подходов к лабораторной диагностике нарушений гемостаза. В этом направлении большие перспективы имеет тест калиброванной тромбографии (тест генерации тромбина), позволяющий с высокой точностью измерять динамику как образования, так и инактивации тромбина - ключевого формента свертывания крови [14-16]. Данный тест реагирует на любые посылы к активации свертывания крови и в связи с этим носит интегральный характер.

Другой новый метод исследования - оценка пространственной динамики роста сгустка фибрина (тромбодинамика) - был разработан в лаборатории физической биохимии Гематологического научного центра РАМН и описан в ряде фундаментальных и прикладных работ $[17,18]$. Анализ проводится в тонком слое плазмы, свертывание в которой активируется тканевым фактором, фиксированным с одной из сторон измерительной кюветы. В ходе исследования ведется фотосъемка растущего сгустка фибрина, параметры которого позволяют судить о динамике фибринообразования во времени и пространстве в двух системах координат [19]. В настоящее время анализатор «ТромбоИмиджер-2» для оценки пространственной динамики роста сгустка фибрина и расходные материалы к нему (разработанные ООО «ГемаКор») проходят клиническую апробацию в российских клинических центрах, в том числе и на базе Алтайского филиала ФГБУ «Гематологический научный центр» в рамках направлений, связанных с изучением эффективности тромбопрофилактики после эндопротезирования суставов и особенностей гемостатических реакций на разных сроках физиологически протекающей беременности.

В заключение отметим принципиальную значимость определения состояния тромботической готовности у носителей постоянных факторов риска, прежде всего у больных тромбофилией, поскольку тромбинемия, депрессия физиологических антикоагулянтов и фибринолиза, наряду со стазом и повреждением сосудистой стенки, предопределяют близкий и далеко не всегда клинически видимый тромбоз. Широкое внедрение лабораторных технологий определения этого состояния позволит получать объективные предпосылки для начала проведения медикаментозной тромбопрофилактики, определения ее необходимой длительности, надежного контроля эффективности лечебнопрофилактических мероприятий.

\section{Список митературы}

1. Баркаган 3.С., Момот А. П. Аиагностика и контролируемая терапия нарушений гемостаза. 3-е иза. М.: НьюАиамеА; 2008. 292 с.

2. Момот А.П. Патология гемостаза. Принципы и алгоритмы кАинико-лабораторной Аиагностики. СПб.: Форма Т; 2006. 208 с.

3. Момот А.П. реА., Цывкина А.П., Тараненко И. А., Мамаев А.Н., СерАюк Г.В., Шахматов И.И. и Ар. Современные методы распознавания состояния тромботической готовности. Барнаул: изА-во А^тайского государственного университета; 2011.138 с.

4. Строзенко А. А., Момот А.П., $\wedge$ банов Ю. Ф., Тараненко И. А., СерАюк Г.В. Факторы тромбогенного риска и состояние зАоровья поАростков г. Барнаула. Мелицина и образование в Сибири: электронный научный журнал. 2012; 2: http://www. ngmu.ru/cozo/mos/article/text full. php?id=6832

5. Harris E., Pierangeli S. Primary, secondary and catastrophic antiphospholipid syndrome: what's in a name. Semin Thromb Hemost. 2008; 34: 219-26.

6. Bovill E., Hasstedt S., Leppert M. et al. Hereditary thrombophilia as a model for multigenic disease. Thromb Haemost. 1999; 82: 662-6;

7. Makris M. Thrombophilia: grading the risk. Blood. 2009; 113 (21): 5038-9.

8. Момот А.П., АыАина И.В., Борисова О.Г. ЕАыкомов В. А., Цывкина А.П. Экстракор поральное оплодотворение и управление гемостазом. Проблемы репродукции. 2012; 6: 47-55.

9. Момот А.П., Сераюк Г.В., Григорьева Е.Е., Селиванов Е.В., Николаева М.Г., Гурье ва В.А. Невынашивание беременности и генетически обусловленные тромбофолии. Вестник Российского университета Аружбы народов. Серия «Медицина. Акушерство и гинекология). 2009; 6: 379-84.

10. Трисьонова Е. А., Габилулина Т.В., Агаркова Т. А. Габитова Н. А., Степанов В. А. Гомоцистеин, полимороризмы гена MTHFR и осложнения беременности. Акушерство и гинекология. $2011 ; 2:$ 8-15.

11. Петрищев Н.Н., реА. Аисорункция эндоте мия. Причины, механизмы, орармакологическая коррекция. СПб.: СПбГМУ; 2003. 184 С.

12. Шойхет Я.Н., Момот А.П. О роли и взаимосвязи гемостатических и воспалитель ных реакций в орормировании очагов гнойной Аеструкции органов и тканей. Проблемы клинической меАицины. 2008; 4 (16): 102-17.

13. Schouten M., Wiersinga W., Levi M., van der Poll T. Inflamation, endothelium, and coagulation in sepsis. J Leukoc Biol. 2008; (suppl.3): 536-545.

14. Момот А.П., АыАина И.В., Цывкина А.П. Борисова О.Г. Роль теста генерации тромбина и некоторых маркёров тромбинемии А^я прогноза исхоАОв экстракорпорального оплодотворения. Гемостазиология. 2011 ; 2: 80-84.

15. Hemker H. C., Giesen P., Al Dieri R., Regnault $V$., De Smedt E., Wagenvoord R. et al. Calibrated automated thrombin generation measurement in clotting plasma. Pathophysiol Haemost Thromb. 2003; 33: 4-15.

16. Hemker H. C., Giesen P., Al Dieri R., Regnault V., De Smod E., Wagenvoord R. et al. The calibrated automated thrombogramm (CAT): a universal routine test for hyper- and hypocoagulability. Pathophysiol Haemost Thromb. 2002; 32 (5-6): 249-53.

17. Синаурилзе Е.И., Буланов А.Ю., Щер бакова О.В., Горбатенко А. С., Атаум^а ханов Ф.И. Усиление коагуляции, вызываемое переливанием искусственных плазмозамещающих растворов. Тера певтический архив. 2009; 81 (1): 52-5.

18. Ovaneson M., Panteleev M., Sinauridze E., Kireev D., Plyushch O., Kopylov K. et al. Mechanism of action of recombinant activated factor VII in the context of tissue factor concentration and distribution. Blood Coagul. Fibrinolysis. 2008; 19 (8): 743-755.

19. Пантелеев М. А., Васильев С. А., Синаурилзе Е.И., Воробьев А.И., реА., Атаумиаханов Ф.И. Практическая коагулология. М.: Практическая медицина; 2011. 192 с. 